\title{
Cadeia da Relação: sonhos de pureza em tempos de (neo)liberalismo ${ }^{1}$
}

\author{
Cadeia da Relação: Dreams of Purity \\ in Times of (Neo)Liberalism
}

\section{Cadeia da Relação: sueños de pureza en tiempos de (neo)liberalismo}

Beatriz Pimenta Velloso *

http://dx.doi.org/10.22409/poiesis.1932.53-72

\begin{abstract}
RESUMO: Na cidade do Porto, a partir de pesquisa realizada no acervo do Centro Português de Fotografia (CPF), situado no edifício da antiga Cadeia da Relação, são apresentados a série de trabalhos denominada Sonhos de Pureza, e o presente texto que narra a história desta Cadeia associada à imigração de portugueses para o Brasil entre os séculos XIX e XX. A pesquisa conceitualmente sugere que as teses criticas de Michel Foucault sobre a sociedade disciplinar e a arqueologia do saber se desdobram na proposta por Bruno Latour de "ecologizar" os conhecimentos, e no conceito de "ecologia de saberes" apresentado por Boaventura dos Santos.

PALAVRAS-CHAVE: arte contemporânea; exclusão social; liberalismo; ecologia de saberes
\end{abstract}

\footnotetext{
“ Beatriz Pimenta Velloso é artista visual e professora adjunta do Departamento de Artes Visuais - Escultura da Escola de Belas Artes da Universidade Federal do Rio de Janeiro, no Brasil (BAE / EBA / UFRJ). Em 2018 desenvolveu pesquisa de pós-doutoramento na Faculdade de Belas Artes da Universidade do Porto (FBAUP).

Email: biapimentav@gmail.com
} 
ABSTRACT: In the city of Porto, based on research carried out in the collection of the Portuguese Center of Photography (CPF), located in the building of the Cadeia de Relação, the serie of works called Dreams of Purity are presented and these text that presents the story of the Jail associated with the immigration of Portuguese to Brazil, between the nineteenth and twentieth centuries. The research conceptually suggests that Michel Foucault's critical theses on the disciplinary society and the archeology of knowledge unfold the current "ecologize" of knowledge proposed by Bruno Latour and in the concept of "ecology of knowledge" presented by Boaventura de Sousa Santos.

KEYWORDS: contemporary art; social exclusion; liberalism; ecology of knowledge

RESUMEN: En la ciudad del Porto, a partir de la investigación llevada a cabo en el Centro Portugués de Fotografía de recogida (CPF), ubicado en el edificio de la antigua Cadeia da Relação se presentan la serie de obras llamada Sueños de Pureza, y el presente texto que cuenta la historia de esta cadena asociada con la inmigración portuguesa a Brasil entre los siglos XIX y XX. La investigación conceptualmente sugiere que las tesis críticas de Michel Foucault sobre la sociedad disciplinaria y la arqueología del saber se desdoblan en la propuesta por Bruno Latour de "ecologizar" los conocimientos, y en el concepto de "ecología de saberes" presentado por Boaventura dos Santos.

PALABRAS CLAVE: arte contemporáneo; exclusión social; liberalismo; ecología de saberes

Como citar: VELLOSO, Beatriz Pimenta. Cadeia da Relação: sonhos de pureza em tempos de (neo)liberalismo. Poiésis, Niterói, v. 19, n. 32, p. 53-72, jul./dez. 2018.

doi: http://dx.doi.org/10.22409/poiesis.1932.53-72

Poiésis, Niterói, v. 19, n. 32, jul./dez. 2018. 


\section{Cadeia da Relação: sonhos de pureza em tempos de (neo)liberalismo}

No edifício da antiga Cadeia da Relação da Cidade do Porto, que desde 1990 passou a abrigar o Centro Português de Fotografia (CPF), a arquitetura e as fotos do arquivo da antiga instituição penal imediatamente apontam para a constante convergência entre os discursos disciplinares e as formas de exclusão. A Cadeia foi construída durante trinta anos consecutivos, sendo inaugurada em 1796, e se manteve em atividade até abril de 1974, quando foi desativada devido ao péssimo estado de conservação em que se encontrava. Projetada para funcionar como Tribunal e Cadeia, repartidos de "forma equitativa", na parte reservada ao Tribunal são visíveis os acabamentos "bem cuidados", enquanto na parte da Cadeia as paredes grossas de granito, encerradas por portas chapeadas de ferro e janelas de grades duplas, denotam técnicas rústicas de origem medieval. O edifício como espaço prisional ainda do Antigo Regime espelhava em seu projeto a hierarquia de ordens sociais estratificadas - o clero, a nobreza, o povo - em espaços divididos entre três pisos. Para destinar o preso ao seu local de confinamento, os funcionários da Cadeia "deviam ter em conta o tipo de crime cometido, o estatuto social do detido e a capacidade [deste] para pagar a carceragem", embora não houvesse legislação própria para este procedimento. (SANTOS, 1999) 


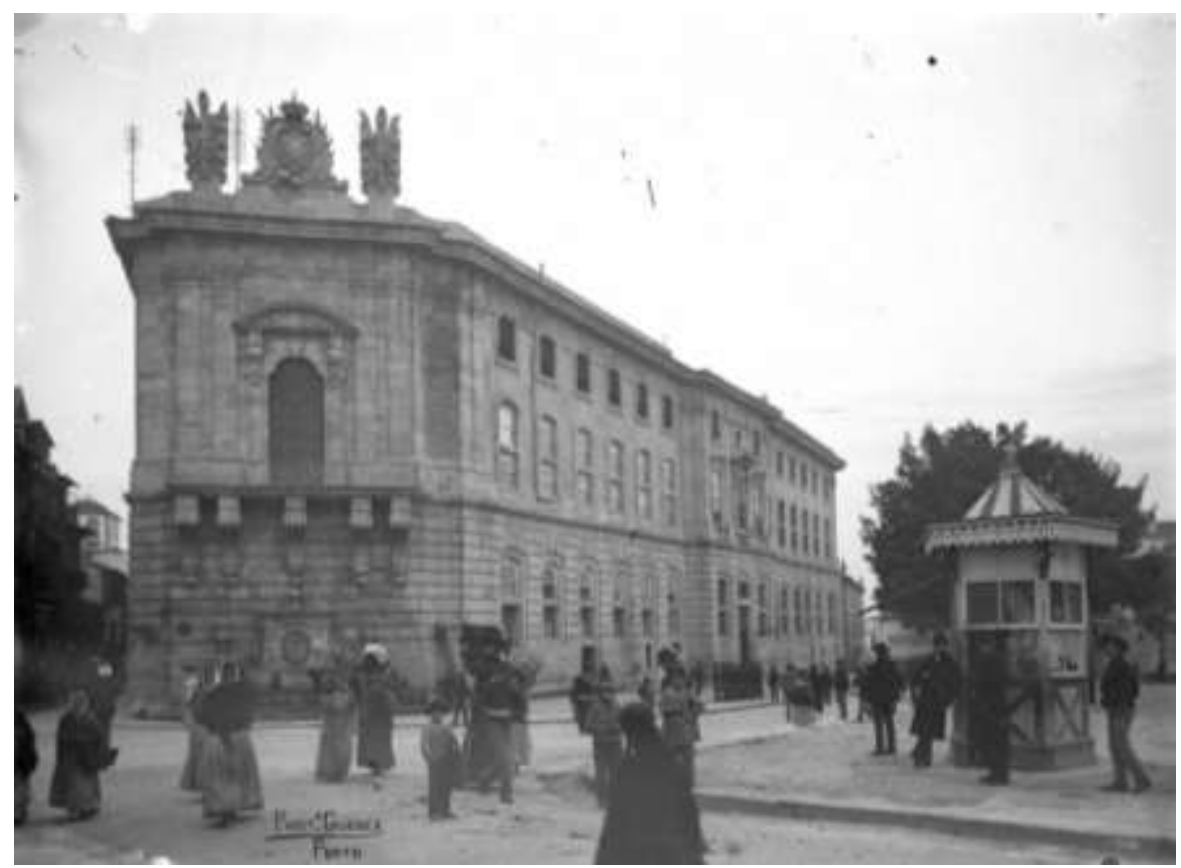

Fig. 1 - Fachada da Cadeia da Relação, cerca de 1900. (Fonte: Photo Guedes)

Poiésis, Niterói, v. 19, n. 32, jul./dez. 2018. 
No primeiro piso, ao nível do rés-do-chão, situavam-se as enxovias - de Santa Teresa, de Santo António, de São Victor, de Santa Rita, do Senhor de Matosinhos e de Santa Ana lajeadas originalmente de granito, escuras, úmidas e frigidíssimas, com acesso apenas por alçapões situados no andar superior. No segundo piso, situavam-se os salões de Nossa Senhora do Carmo e de São José e a saleta das mulheres, também espaços coletivos, mas mais salubres. No último piso ficavam os quartos de Malta, concebidos como prisões individuais para "pessoas de condição" que se encerravam apenas durante a noite. [...] Para além destas áreas a cadeia dispunha ainda [...] de um oratório dos réus condenados à morte, no $1^{\circ}$ piso; de diversos "quartos para presos incomunicáveis", e de uma "capela dos presos" de estrutura em madeira, adossada à parede do saguão principal, onde era celebrada a missa. (SANTOS, 2011)

Considerando o atraso de Portugal em relação à França e à Inglaterra, "o conceito de prisão penitenciária que se divulgou no século XIX entrou, desde logo, em conflito com esta velha prisão setecentista", mas sua curiosa "planta trapezoidal" e as de paredes grossas e fechadas entre si ajudaram a conservar o edifício, pois "não houve hipótese de criar celas, nem, tão pouco, alojamentos totalmente isolados para mulheres e menores, refeitórios, balneários etc.", como exigia o novo modelo prisional. A impossibilidade de implantar efetivamente esse modelo, somada ao fluxo de migrantes que vinha das fazendas para a cidade, contribuiu para que a Cadeia da Relação não atingisse a meta de disciplinar e de incluir na sociedade a crescente população carcerária que dentro se estabeleceu. (SANTOS, 1999, p. 104)

No Tribunal da Relação, o livro L'uomo delinquente, do médico Cesar Lombroso, publicado em 1876 na Itália, foi uma das primeiras referências teóricas sobre criminologia. Entretanto, a hipótese de existência do "criminoso-nato", de "degeneração atávica", sugeria que a cadeia não poderia ser um meio para a regeneração de criminosos, mas o encaminhamento para a pena de morte ou para o degredo. Em 1895, Lombroso acrescenta um Atlas de imagens à sua pesquisa, agora ampliada e traduzida para o francês sob o titulo de Tratado antropológico experimental do homem delinquente. A partir de álbuns etnográficos, fotografias de crâneos de hominídeos e antropoides, vários tipos de retratos in- 
cluindo o de rebeldes da Comuna de Paris, o Atlas simula modelos para predestinar traços do delinquente, tipificar raças superiores e inferiores, identificar doenças mentais e temperamentos criminosos, o que se provou infundado, visto que entre a morfologia de crâneos, traços fisionômicos, predominância étnica e a capacidade intelectual, o temperamento emocional de um individuo, não existem correspondências. Porém, lamentavelmente, os estudos de Lombroso contribuíram para a formação do ideário fascista italiano e o nazismo alemão, que persiste ecoando nas redes sociais, eclodindo em agressões e atentados xenofóbicos dispersos.

Em 1902, no estabelecimento do Posto Antropométrico e a respectiva sessão fotográfica na Cadeia, houve influência direta do médico francês Alphonse Bertillon, criador do sistema de identificação criminal baseado nas medidas do corpo humano e através do retrato policial. Posteriormente, este médico-criminalista montou uma tabela para catalogar diferentes morfologias humanas - orelhas, narizes, perfis, testas, formas de rosto, entre outras partes do corpo -, para auxiliar na construção de retratos falados. Este método funcional que atualmente é aplicado através de computadores, ainda que não seja prova definitiva em um inquérito, desde sua invenção sempre favoreceu a discriminação étnica.

Paralelamente aos métodos e teorias para a identificação de criminosos no final do século XIX, os Congressos de Antropologia Criminal, realizados em Lyon na França, trazem ao debate ideias sociológicas de Alexandre Lacassagne, Gabriel Tarde e Emile Durkeim, que apontam fatores econômico-sociais como as principais causas do crime. Hoje, não é difícil constatarmos a veracidade dessa hipótese no arquivo referente à antiga Cadeia, quando vemos sobre o fundo de paredes encardidas e úmidas, mulheres e homens de pés descalços, lenços rasgados, camisas abertas, mangas esgarçadas, braços em cruz, corpos encostados contra a parede ou fixos a um suporte para o pescoço, embora na época essa técnica já estivesse ultrapassada. Mergulhada nos originais desses retratos do arquivo da Cadeia da Relação, a jornalista Maria do Carmo Séren constata, "do índice desinvidualizado e nu que é a fotografia judiciária, só nos chegam, a este lado do tempo, os vagos murmúrios de um constrangimento que foi deles e que agora é inteiramente nosso". (SERÉN, 1999, p. 31)

Poiésis, Niterói, v. 19, n. 32, jul./dez. 2018. 
A maioria dos presos que passavam pela Cadeia de Relação vinha das Ilhas do Porto. Originalmente denominou-se de Ilha aos conjuntos de pequenas casas, que começaram a surgir na parte oriental da cidade durante o século XVIII, conjuntos que utilizavam uma mesma saída para a rua e que não eram visíveis da rua; algumas fontes atribuem a morfologia das Ilhas à influência de vilas operárias inglesas. Com a vinda de migrantes das áreas rurais entre 1878 e 1890, teriam sido construídas 5.100 habitações sob a forma de Ilhas, onde habitava "em 1989, um terço (1/3) da população da cidade". (PINTO, 2007) O ambiente das Ilhas, com a superlotação de casas minúsculas e a crescente miséria dos moradores, estimulava a prática de furtos e de roubos pelas ruas da cidade, o que levava muitos de seus habitantes para a Cadeia, criando um círculo vicioso entre duas instâncias igualmente perversas. (Fig. 5)

Com o aumento do número de presos na Cadeia da Relação, seus ambientes tornaram-se ainda mais insalubres, propícios a contração de doenças que se propagavam extensivamente nas Ilhas. A falta de ocupação e as péssimas condições de vida nas enxovias proporcionou em seu interior a formação de uma verdadeira escola do crime e, consequentemente, o progressivo aumento da população carcerária. Pela falta de instituições que abrigassem órfãos, idosos e pacientes psiquiátricos, a Cadeia também foi destinada a abrigar essa gente, transformando seus espaços em um verdadeiro depósito de excluídos sociais, que separava apenas os homens, distribuídos pelos grandes ambientes das enxovias ao rés-do-chão, das mulheres, destinadas a permanecer em uma única sala no segundo piso. No correr do século XIX, com Portugal sob o domínio do Liberalismo, a solução foi incentivar a população marginalizada a emigrar para o Brasil e degredar os presos para as colônias da África, onde poucos conseguiam sobreviver e voltar. Segundo Santos (1999), o considerável atraso industrial de Portugal em relação a outros países da Europa e o crescimento demográfico rural ocorrido no país a partir de 1830, com fluxos migratórios rumo às cidades maiores, como Lisboa e o Porto, "não suscitou, asfixiante pressão social desencadeadora de conflitos insolúveis, como aconteceu noutros países, na medida em que a emigração, sobretudo para o Brasil, absorveu esse excesso de população que a nossa incipiente indústria não podia enquadrar". (SANTOS, 1999, p. 351) 


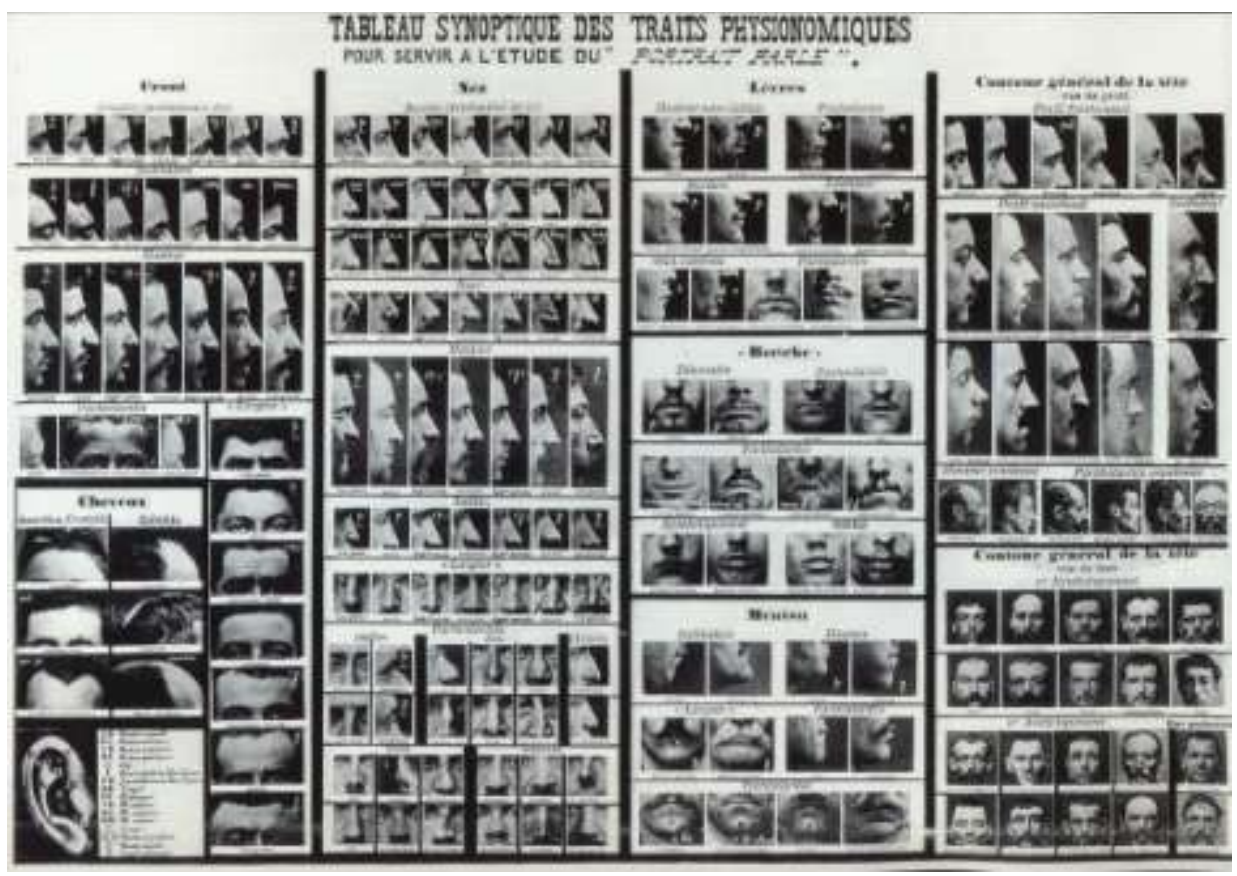

Fig. 2 - Alphonse Bertillon, Tableau synoptic des traits physionomiquese, 1909. gelatina de prata, $20 \times 29 \mathrm{~cm}$

(Fonte: Metropolitan Museum of Art, Fotografia do século XX, 2009)

Poiésis, Niterói, v. 19, n. 32, jul./dez. 2018. 


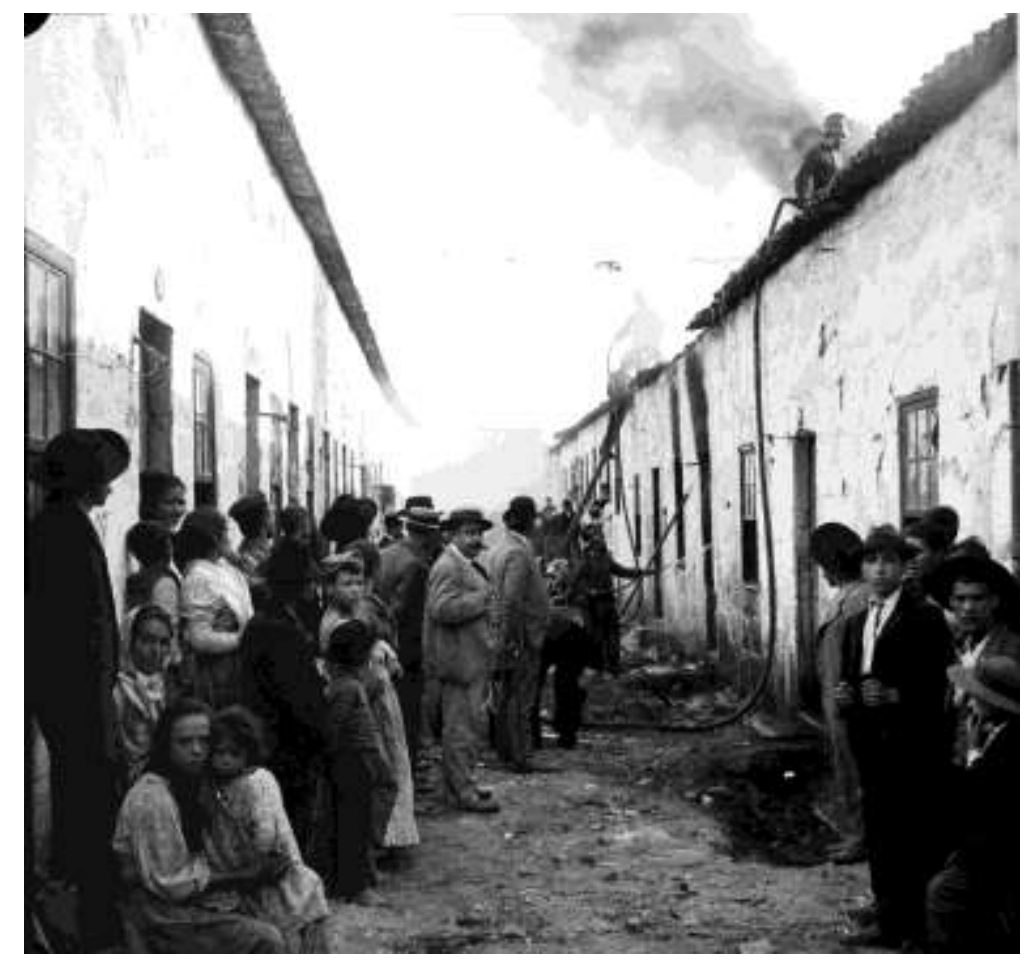

Fig. 3 - Bombeiros em combate sanitário à peste bubônica nas Ilhas do Porto, 1899. (Fonte: Fonte: Arquivo do Centro Português de Fotografia) 
Porém, as condições oferecidas aos imigrantes portugueses por D. Pedro I no Brasil ${ }^{2}$ eram péssimas, desde a viagem em navios superlotados até o que os esperava na chegada. Muitos trabalhavam nas cidades como estivadores, puxadores de carrinhos (burros sem rabo) etc., e outros, quase como escravos, nas lavouras dos latifúndios. Ainda haviam os que deviam as passagens aos donos de navios: estes costumavam ser leiloados aos proprietários de terra, que saudavam a dívida dos imigrantes sob a condição de que estes trabalhassem sem salários até pagarem o que deviam ${ }^{3}$. Com o tempo, para os imigrantes portugueses que conseguiam acumular algum recurso, era comum criarem pequenos comércios na cidade, agregados às casas onde viviam. No Brasil República, no esforço para economizar cada centavo, o português era visto pelas classes populares brasileiras "como galego sujo, sem escrúpulos, mesquinho, burro-de-carga ou avarento". Os galegos originalmente eram "imigrantes espanhóis da Galiza", que antes de emigrarem para o Brasil, dirigiam-se para as cidades de Lisboa e Porto, onde exerciam ofícios temporários enquanto ficavam à espera de navios. O termo, de início usado por portugueses para discriminar os espanhóis que thes ofereciam concorrência, acabou sendo apropriado por brasileiros como forma de provocação. (MARTINS, 2007, p. 201)

0 "galego" era aquele emigrante, normalmente o português dono de botequim ou de pensão, que estava em contato direto com as classes mais baixas da população e que para conseguir ascender economicamente não poupava meios, roubando a clientela, vendendo produtos de pior qualidade ou vivendo em condições precárias para juntar a sua sonhada fortuna. ${ }^{4}$

Em 2018, vivendo na cidade do Porto por um ano, o contato diário com portugueses no comércio, a princípio traz lembranças das quitandas, botequins e padarias de esquina, tão comuns em qualquer bairro do Rio de Janeiro até os anos de 1990. A lentidão do atendimento, a atenção reservada a cada cliente, o modo de atender um pedido de cada vez ainda se faz presente no Porto. O que de início pode causar profunda irritação, depois torna-se um hábito, que nos faz entrar em uma temporalidade mais lenta, na qual há espaço para uma conversa, seja sobre o artigo que estamos comprando, seja sobre as condições climáticas ou qualquer outra coisa. Portugal sempre se sentiu pequeno em relação aos

Poiésis, Niterói, v. 19, n. 32, jul./dez. 2018. 
países "maiores e mais avançados" da Europa. Em substantivos e adjetivos da língua portuguesa, o insistente uso de diminutivos enfatiza essa ideia de menor, de minoria, que escapa ao modelo dominante e que soma-se a uma espécie de raiva contida, traduzida pela literalidade da fala portuguesa, às vezes sem nenhuma sutileza. Os nomes e pronomes utilizados na terceira pessoa, sem o diferencial condicional, se apresentam sempre em uma forma defensiva, supondo uma impossibilidade. Eu "gostava" de estar com você. Assim aos poucos vamos nos afeiçoando ao modo-de-vida português, identificando sua influência na sociedade brasileira.

Nas sucessivas crises da contemporaneidade, Portugal, como país de clima ameno, estabilidade política, boa infraestrutura, baixo custo de vida em relação aos padrões da União Europeia, se tornou um lugar atraente para os cidadãos europeus e imigrantes de todas as partes. A miscigenação entre cristãos, judeus e árabes, fundamental na formação da cultura portuguesa, o atraso industrial, a permanência do fazer artesanal, antes considerados como sinal de atraso, fraqueza de caráter ou falta de inteligência, atualmente - entre crises, atentados terroristas, ataques xenofóbicos, mudanças climáticas - podem ser vistos como casualidades positivas. Há muitos brasileiros que vêm para o Porto como investidores, outros em busca de trabalho, uns apreciam o conservadorismo das tradições sociais, outros, mais jovens, dinamizam uma sociedade na qual os idosos predominam. Embora venha gente de todas as partes do Brasil, com diferentes ideários e crenças, todos vêm em busca de uma vida melhor.

\section{Modernidade, sociedade disciplinar e exclusão social}

Dos dados levantados nesta breve pesquisa realizada na biblioteca e no acervo da Cadeia da Relação, destaca-se a sincronia aparentemente paradoxal entre o domínio do Liberalismo em Portugal e o rápido crescimento da população carcerária do Porto. O mesmo Liberalismo que por um lado beneficiou o pequeno campesinato, a pequena burguesia, a industrialização, a reforma da saúde, a reforma fiscal e administrativa, por outro lado proporcionou o rápido aumento da população de excluídos sociais, que sem opções foi obrigada a emigrar. Com a chegada desses imigrantes à recente república do Brasil, os 
conflitos entre os portugueses e brasileiros mais humildes (escravos recém-libertos, mestiços e outros imigrantes) tornaram-se constantes, enquanto o Estado "ficava de fora, observando de longe como o povo, sem meios educacionais e sem perspectivas de melhoras, se engalfinhava e cobrava seus direitos na mercearia ou no botequim do português". (MARTINS, 2007, p. 201) É importante destacar que houve portugueses que também foram excluídos, mas não se trata de mensurar quem foi o mais excluído (obviamente, em termos gerais, foram indígenas, africanos e afrodescendentes), mas de entender as relações inter-humanas no Brasil. O longo período de escravidão, a heterogeneidade étnica, as precárias condições de vida oferecidas aos trabalhadores, as pontuais melhorias do Império enquanto se refugiou na cidade do Rio de Janeiro, os intermitentes projetos do Estado para diminuir as desigualdades sociais desde o inicio da colonização até hoje têm contribuído para a fragmentação política entre grupos pertencentes às classes média e baixa brasileiras, não constituindo uma aliança forte o suficiente para enfrentar o poder de uma pequena elite renitente, decidida a não perder seus privilégios.

Na critica à uma narrativa histórica unificada, construída a partir de um ponto de vista hegemônico, Foucault (2009) nos sugere em sua "arqueologia do saber" a substituição de unidades estruturais do pensamento historicista, tais como "tradição, influência, desenvolvimento, evolução, fonte e origem", por conceitos como "descontinuidade, ruptura, limiar, limite e transformação", a partir dos quais podemos pensar a industrialização, o desenvolvimento das cidades, o crescimento populacional e a emigração de portugueses para o Brasil como descontinuidades de vários saberes e modo-de-vidas em diferentes comunidades portuguesas pré-industriais.

De modo geral, a história da cultura ocidental, que foi construída a partir de invasões, saques e violentos processos de colonização, se traduz melhor como uma série de rupturas que marcam o fim de tradições europeias, o fim de povos das Américas, da África e da Oceania, para a transformação destes em algo que não mais corresponde às suas origens, desviando sempre que possível de suas influências. Se na sociedade disciplinar descrita por Foucault (2015), as modernas instituições de confinamento como "o hospício, a clínica e a prisão, e suas estruturas discursivas respectivas - loucura, doença e criminalidade",

Poiésis, Niterói, v. 19, n. 32, jul./dez. 2018. 
são nitidamente formas de exclusão, as escolas, as disciplinas e os museus, igualmente como instâncias de controle, são "genealogias do poder" que preservam e produzem o conhecimento especializado, coibindo a ocorrência de práticas independentes do sistema dominante.

À margem da História, depois de séculos de exploração e de extermínio de vários povos do planeta, a antropologia surgiu como uma ciência no início do século XIX sob a influência do evolucionismo darwiniano, com o objetivo de estudar povos que resistiram vivendo afastados da colonização. Com o aprofundamento dessas pesquisas, na busca de entender sociedades tão diferentes, a antropologia se vincula às ciências sociais iniciando a construção de um método único, interdisciplinar, em constante adequação. Se na antropologia moderna a relação entre as culturas foi considerada assimétrica, porque era o antropólogo como sujeito que descrevia o nativo como objeto, na visão pós-moderna a relação de sujeito para sujeito tentou evitar a assimetria de posições. Para escapar do relativismo de posições subjetivas, comum à proposição pós-moderna, a antropologia simétrica proposta por Bruno Latour (1994) procura equilibrar conceitualmente essas relações, não considerando o conceito de cultura isolado da natureza que the corresponde. Assim, as naturezas-culturas, com seus respectivos "seres humanos, divinos e não-humanos", passam a constituir um conjunto significante que não pode ser fragmentado, sobretudo quando se trata de comparar objetos, mitos ou ritos referentes a diferentes povos. No pensamento de Latour, o complexo natureza-cultura é extensivo às polaridades do pensamento moderno, humanos e não-humanos, sujeito e objeto, masculino e feminino, entre outras, que deixam de ser estruturas "diferenciais" para tornarem-se entes "coextensivos". A separação entre as ciências humanas das ciências sociais, o desenvolvimento de disciplinas de forma isolada são sintomas de uma modernidade que se estruturou em pólos de "pureza", captando o trabalho dos "híbridos", mas invisibilizando sua presença e proliferação em meio ao que foi projetado. (LATOUR, 1994) O aumento de "CO2" produzido pela queima de combustíveis fósseis, o lixo da produção industrial, a transformação de naturezas-culturas pelos processos de colonização constituem exemplos dessas hibridizações que escapam ao planejado. Em 2014, quando foi amplamente divulgado "que a 
civilização industrial poderia entrar em colapso dentro dos próximos cem anos devido a mudanças climáticas antropogênicas", Latour não foi pego de surpresa, visto que depois de se aprofundar conceitualmente nos motivos que levaram à falência o projeto moderno, de explicitar a necessidade de "ecologização" entre a politica e o conhecimento cientifico, de reconhecer no mundo a nossa interdependência de não-humanos (deuses, ecossistemas, maquinas, aparelhos), já estava em meio a difícil tarefa de pensar um povo capaz de interagir com Gaia5 ${ }^{5}$ (LATOUR, 2015, p. 43)

Em tempos de crise, cabe a nós pesquisadores colaborarmos na construção de tramas, redes que integrem pensadores transdisciplinares e interdisciplinares aos "conhecimentos populares, leigos, plebeus, camponeses, indígenas" como premissas programáticas de uma "ecologia de saberes". Termo que identifica os encontros propostos pelo sociólogo português Boaventura Santos (2007), compostos por representantes de diferentes fazeres - artistas, produtores culturais, culinárias, cultivos, advogados, entre outros - para que se façam trocas, atravessamentos e interconexões entre os saberes pré-modernos, as ciências humanas e as ciências sociais. Boaventura (2007) nos fala que "o pensamento moderno ocidental é um pensamento abissal. Consiste num sistema de distinções visíveis e invisíveis, sendo que as invisíveis fundamentam as visíveis". As linhas abissais iniciaram-se em territórios bem definidos, separando a visibilidade das metrópoles da invisibilidade das colônias; no pós-colonialismo essas linhas continuaram existindo de forma sinuosa, dividindo áreas de exclusão e de cidadania dentro das metrópoles do mundo globalizado. O autor sugere, a fundamentação de outras "epistemologias" para transpormos este abismo, visto que nas antigas colônias a lei aplicada aos povos nativos, antes considerados sub-humanos, foi a de "apropriação e violência", radicalmente diferente da lei utilizada para lidar com a população de excluídos europeus, que era de "regulação e emancipação". (SANTOS, 2009)

Com as devidas diferenças, conclui-se que o que foi "invisibilizado", segundo Boaventura Santos, tem correspondências com as "entidades híbridas" de Latour, sendo as "instituições de confinamento" definidas por Foucault um mapeamento fundamental dos mecanismos de exclusão da modernidade. Contudo, é importante destacar que junto à exclu-

Poiésis, Niterói, v. 19, n. 32, jul./dez. 2018. 
são social, operada de diferentes formas nas metrópoles e nas colônias, muitos saberes foram perdidos pela modernidade, ainda que alguns persistam constituindo alternativas para a crescente insustentabilidade das práticas neoliberais, as quais, nos países ricos, têm acelerado a degradação dos ecossistemas e as mudanças climáticas, enquanto nos países pobres têm aumentado a desigualdade social, inviabilizando a desejada expansão econômica.

\section{Sonhos de pureza}

Paralelamente a esta pesquisa, foi desenvolvida uma série de trabalhos em fotografia e vídeo a partir de imagens captadas no antigo edifício da Cadeia da Relação. Denominada Sonhos de Pureza, esta série apresenta o liberalismo e a exclusão social como duas faces de uma mesma moeda que circula livremente pelo mundo globalizado. 

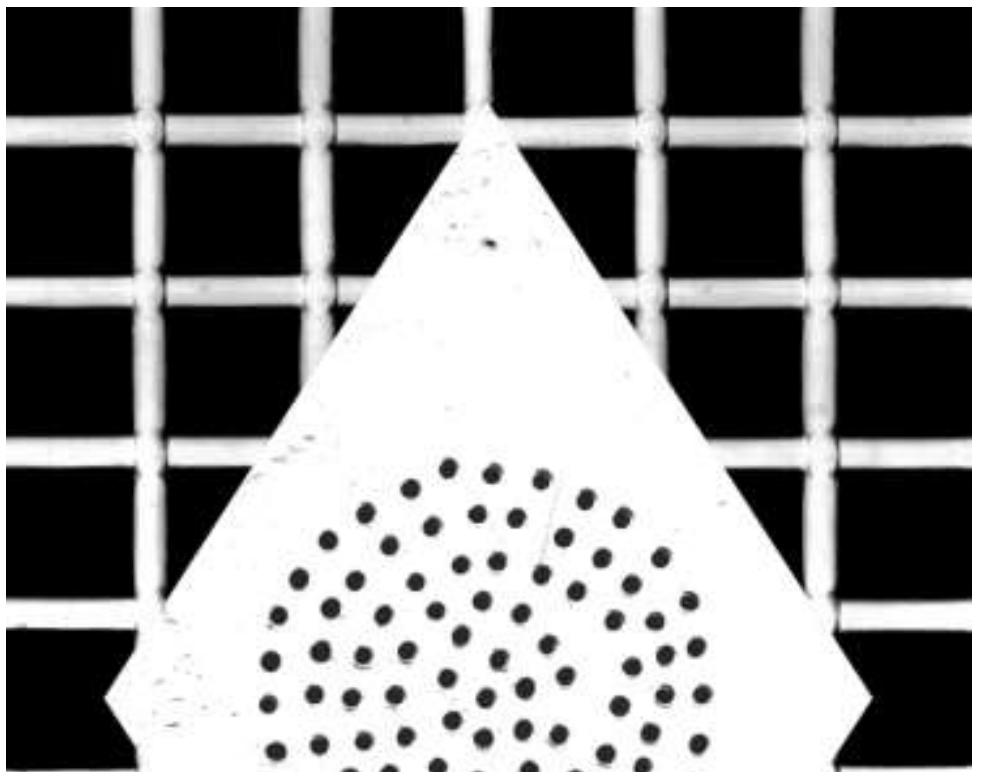

$\because \bullet \because \bullet$

- e e e

-
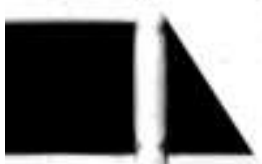

- $\bullet \bullet \bullet$ $0_{0}^{\circ}$
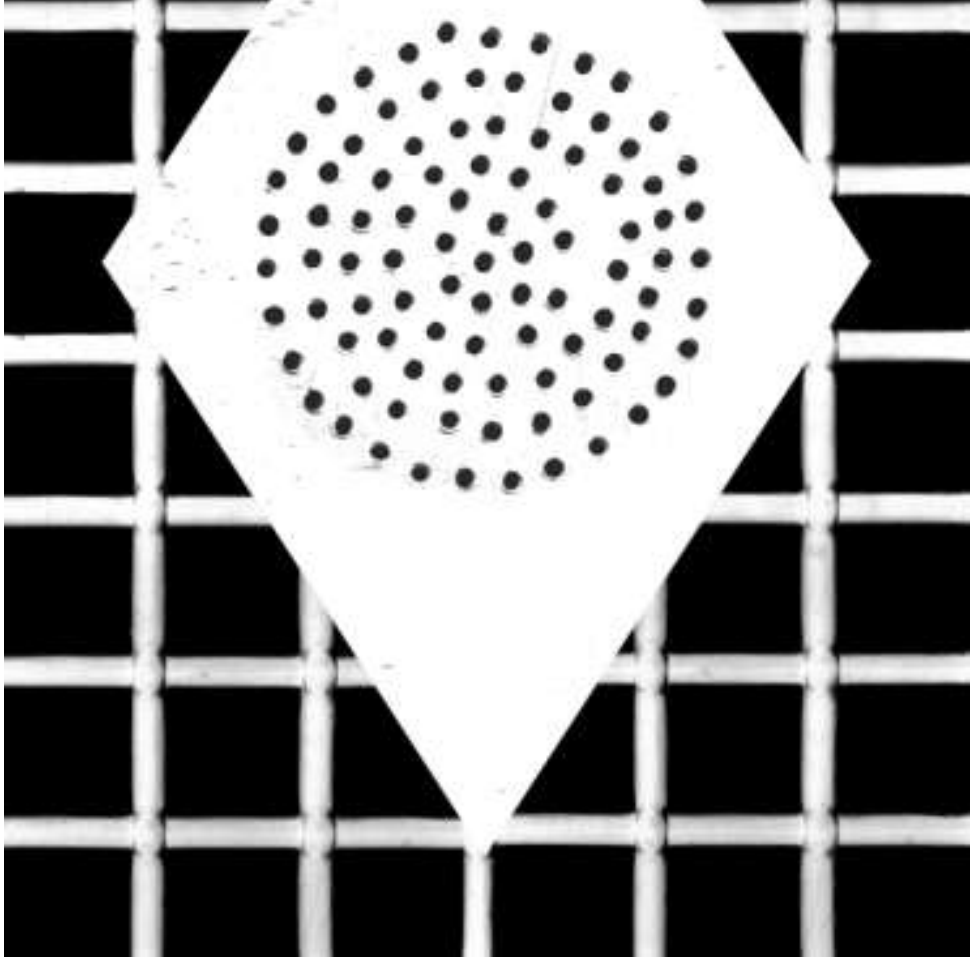

Fig. 4 - Beatriz Pimenta Velloso, Sonhos de Pureza, 2018.

impressão sobre tecido flag, $150 \times 100 \mathrm{~cm}$

Poiésis, Niterói, v. 19, n. 32, jul./dez. 2018. 


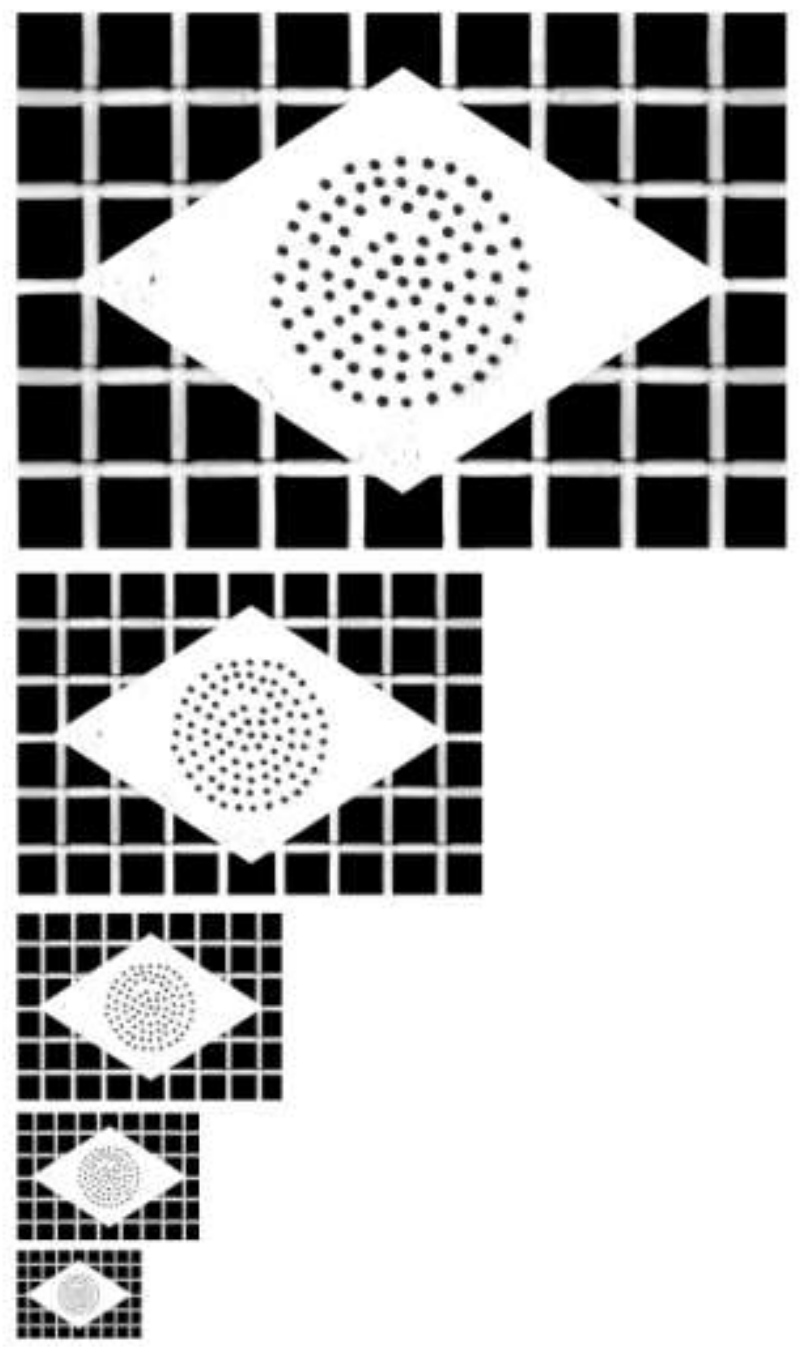

Fig. 5 - Beatriz Pimenta Velloso, Sonhos de Pureza (teste de escala), 2018. 


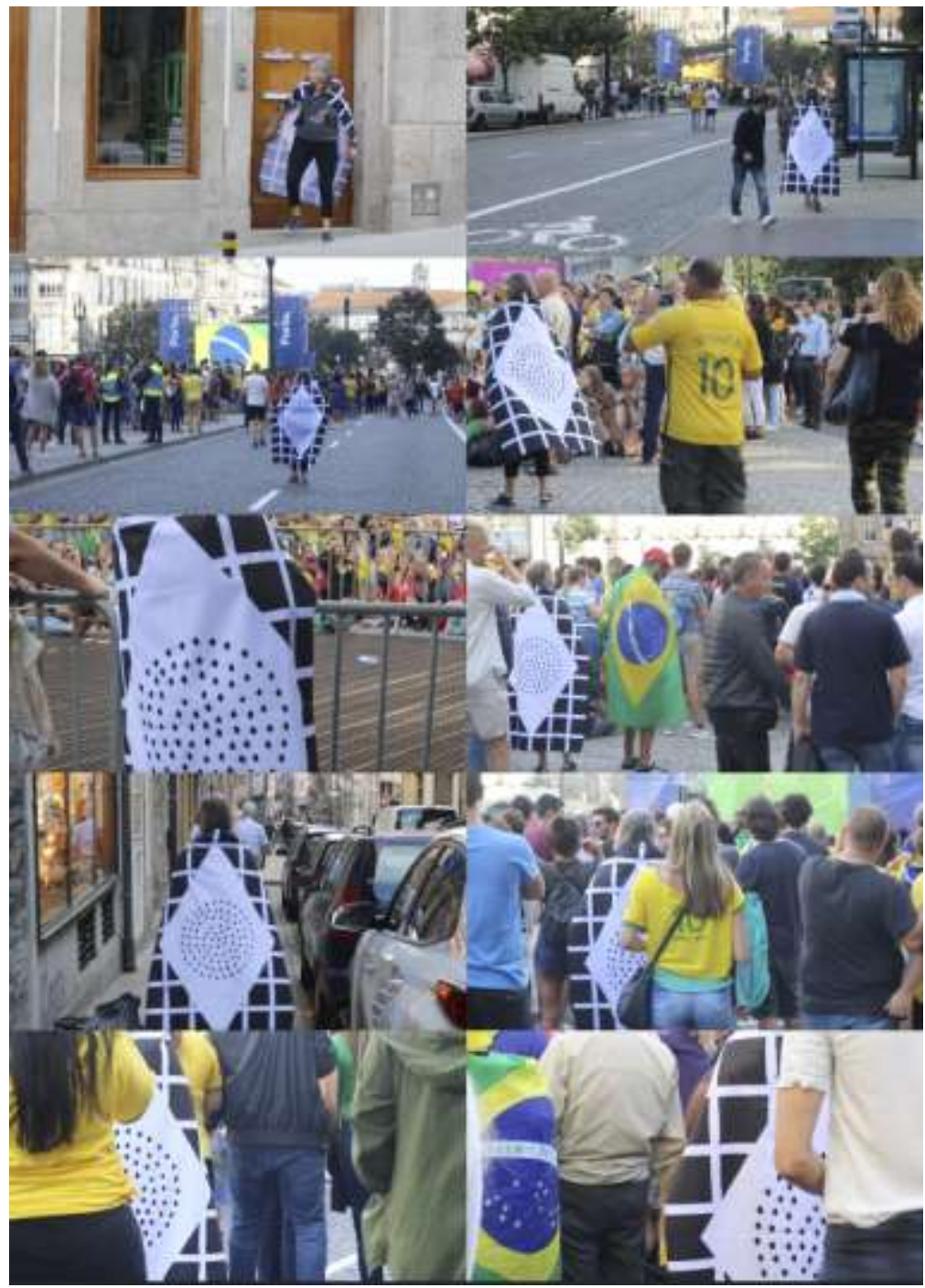

Fig. 6 - Beatriz Pimenta Velloso, Sonhos de Pureza (teste de contraste), 2018. 


\section{Notas}

10 texto e os trabalhos a seguir foram desenvolvidos durante 2018 em estágio pós-doutoral realizado na Faculdade de Belas Artes na Universidade do Porto (FBAUP).

2

A princípio, a tarefa de incentivar a imigração foi assumida pelo poder central do recém-criado Império brasileiro, cujo imperador era o português D. Pedro I (ou Pedro IV, entre os lusos). Entretanto, o papel de gestor do projeto de imigração foi atribuído às Províncias do Império pelo Ato Adicional de 1834 e, depois da instalação da República, em 1889, aos Estados (o que não quer dizer que o poder central tenha se eximido do assunto). (Charleston José de Sousa Assis e Leila Menezes Duarte apud MARTINS, 2007, p.144)

3

Assim descreve o Conde de Tomar as condições de imigração nas llhas de Açores: o emigrante que parte das ilhas "não tem dinheiro para pagar as passagens para o Brazil, obriga-se por uma escriptura pública a todo o serviço, que the fôr designado, e por tanto tempo, quanto fôr necessario para pagar a passagem: chegados ao Brazil eis os Açorianos no mercado, a quem mais dá, e de lá vão os Brazileiros compra-los temporariamente!". Insistindo na imagem de tráfico de escravatura branca, termina sua intervenção, concluindo com alguma mordacidade: “não é isto vergonhoso ao nome Portuguez? E há-de consentir-se tal?" (Fernanda Paula Sousa Maia apud MARTINS, 2007, p. 55)

4

Os galegos originalmente eram imigrantes espanhóis da Galiza, que antes de emigrarem para o Brasil de forma massiva, dirigiam-se para as cidades de Lisboa e Porto, onde exerciam ofícios populares temporariamente. 0 termo de inicio usado por portugueses para discriminar espanhóis que lhes ofereciam concorrência, acabou sendo apropriado por brasileiros, entre empregados e fregueses, que se sentiam explorados e maltratados pelos portugueses donos de pequenos negócios. (Érica Sarmento da Silva apud MARTINS, 2007, p. 201)

${ }^{5}$ Facing Gaia é o livro em que Latour explora o conceito de "Gaia", proposto por James Lovelock para explicitar o sistema frágil e complexo através do qual os fenômenos vivos modificam o planeta Terra. Através de uma série de palestras, o autor argumenta que a figura complexa e ambígua de Gaia oferece, ao contrário de uma nova proposta de religião, uma forma conceitual para desvendar os aspectos éticos, políticos, teológicos e científicos da noção agora obsoleta de Natureza. 


\section{Referências}

FOUCAULT, Michel. Arqueologia do Saber. Rio de Janeiro: Forense Universitária, 2009.

FOUCAULT, Michel. Vigiar e Punir. Petrópolis: Vozes, 2013.

LATOUR, Bruno. Jamais fomos modernos: ensaio de antropologia simétrica. Rio de Janeiro: 34, 1994.

LATOUR, Bruno. Diplomacy in the Face of Gaia: Bruno Latour in Conversation with Heather Davis. In DAVIS, Heather. TURPIN, Etienne. Art in the Anthropocene: Encounters Among Aesthetics, Politics, Environments and Epistemologies. Londres: Open Humanities Press, 2015.

MARTINS, Ismênia de Lima; SOUSA, Fernando; PEREIRA, Conceição Meireles (Org.). $A$ emigração portuguesa para o Brasil. Porto: Afrontamento, 2007. Disponível em http:// www.cepese.pt/portal/pt/publicacoes/obras/a-emigracao-portuguesa-para-o-brasil. Acesso em_30/10/2018.

PINTO, Jorge Ricardo. O Porto Oriental no final do século XIX: Um retrato urbano (18751900). Porto: Afrontamento, 2007.

SANTOS, Boaventura de Souza. Para além do pensamento abissal: das linhas globais a uma ecologia de saberes. Revista Crítica de Ciências Sociais, n. 78, p. 3-46, out. 2007. Disponível em https://www.ces.uc.pt/myces/UserFiles/livros/. Acesso em 30/10/2018.

SANTOS, Boaventura de Souza; MENEZES, Maria Paula. Epistemologias do sul. Coimbra: Almedina, 2009.

SANTOS, Maria José Moutinho. A sombra e a luz: as prisões do Liberalismo. Porto: Afrontamento, 1999. Disponível em https://www.researchgate.net/publication/259740664_A_Sombra_e_a_Luz_As_Prisoes_do_Liberalismo. Acesso em 30/10/2018.

SANTOS, Maria José Moutinho. O Edifício. Porto: CPF, 2011. Disponível em http://www.cpf.pt/edificio.htm. Acesso em 30/10/2018.

SERÉN, Maria do Carmo. Murmúrios do tempo. Porto: CPF, 1997.

Poiésis, Niterói, v. 19, n. 32, jul./dez. 2018. 